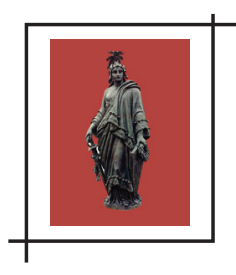

\title{
NECESSIDADE OU LIBERDADE: UMA DISCUSSÃO A PARTIR DO ROMANCE DE DIDEROT, JACQUES, O FATALISTA
}

\author{
Graciela Deri de Codina ${ }^{1}$ \\ (In memoriam)
}

Resumo: 0 propósito deste artigo é pensar a reflexão de Denis Diderot na relação com sua filosofia, a partir do romance Jacques, o fatalista. Considerando a extensão da obra de Diderot; que não é um filósofo sistemático e sim um autor que aponta em diversas direções, portanto interdisciplinar, e porque o que costuma se denominar o romance Jacques, o fatalista é, na verdade, o antirromance. Diderot deve ser situado no contexto histórico do século XVIII, no qual os pensadores que costumamos denominar iluministas inauguram novas maneiras de pensar, uma nova racionalidade que irá além das ideias claras e distintas, que se insurge contra os sistemas fechados e que se abre para a criticidade, para a polêmica apaixonada, enfim, tudo aquilo que anuncia a Revolução Francesa.

Palavras-chave: Liberdade. Iluminismo. Romance. Revolução Francesa. Racionalidade.

0 propósito deste texto é pensar a escrita paradoxal de Diderot na relação com sua filosofia, analisando o romance Jacques, o fatalista. Este projeto é ambicioso por vários motivos: pela extensão da obra de Diderot; porque é preciso considerar que ele não é um filósofo sistemático e sim uma borboleta cujo pensamento voa em diversas direções e porque o que costuma se denominar o romance Jacques, o fatalista é, na verdade, o antirromance. Diderot deve ser situado no contexto histórico do século XVIII, no qual os pensadores que costumamos denominar iluministas inauguram novas maneiras de pensar, uma nova racionalidade que vai além das ideias claras e distintas, que se insurge contra os sistemas fechados e que se abre para a criticidade, para a polêmica apaixonada, enfim, tudo aquilo que anuncia a Revolução Francesa.

Nesse contexto, quiçá a melhor abordagem que possamos fazer para começarmos a refletir sobre este "romance" seja a de levar a sério a advertência do próprio autor, cito: "Repito-vos, portanto, de uma vez por todas: sêde circunspectos, se não quereis tomar na conversa

1 - Doutora em Filosofia pela Unicamp, professora de Filosofia na Universidade Presbiteriana Mackenzie. 
de Jacques e seu amo o verdadeiro pelo falso, o falso pelo verdadeiro. Ei-vos mais que prevenidos, e lavo minhas mãos" (DIDEROT, 1962, p. 79).

No entanto, o que é a verdade e a falsidade neste contexto? A verdade se situa no nível da narração, na materialidade da vida ou, no limite, na filosofia? A narrativa constitui um diálogo que funciona em dois planos: o diálogo entre Jacques e seu amo e o diálogo do narrador com o leitor, em ambos inexiste a possibilidade de estabelecer uma verdade ou uma solução à questão filosófica, ao paradoxo entre a liberdade-acaso e a necessidade.

Em primeiro lugar, o diálogo entre as duas personagens que se confrontam em duas posições diametralmente opostas, não há no romance um juiz que possa resolver quem vence a disputa verbal na medida em que o narrador não assume esse papel, apesar de esclarecer que poderia fazê-lo. Em segundo lugar, no diálogo que o narrador mantém com o leitor, não pode nem deve haver, justamente pelo fato de se tratar de um diálogo aberto, uma instância que defina a verdade, já que as escolhas do autor são meras possibilidades entre muitas outras que poderiam ser aventadas e, portanto, a abertura do diálogo propicia tantas interpretações e escolhas quantos leitores houver.

Na mesma medida em que o narrador se recusa a ser juiz da discussão e apela para que o leitor decida, este último poderia representar uma possível instância de verdade, no entanto, múltiplas interpretações são viáveis. Numa passagem do romance lemos:

\footnotetext{
0 Amo - [...] Não obstante, fala à tua maneira, eu te escutarei à minha, e acreditarei em ti como puder.[...]

Jacques - Se quase nada se diz neste mundo que seja ouvido como a gente o diz, há ainda pior, é que quase nada se faz que seja julgado como a gente o faz.

0 Amo - Não há talvez sob o céu outra cabeça que contenha tantos paradoxos como a tua (DIDEROT, 1962, p. 71-72).
}

Nesse sentido, seria possivel afirmar que se o leitor representa uma instância de verdade é porque toda e qualquer verdade é possivel. A verdade pode estar em qualquer um dos dois planos do diálogo ou em nenhum, o que nos conduz necessariamente a uma ambiguidade que é estética e, simultaneamente, moral e natural. Com efeito, é impossível separar os três niveis e, assim, a pergunta sobre em qual deles a verdade poderia surgir e se instalar é pulverizada, ao igual que qualquer verdade metafísica, moral ou teológica, ambas, a pergunta e a verdade, tornam-se sem sentido.

Na nossa interpretação, a escrita de Diderot no Jacques se desenvolve na ambiguidade entre a ficção da viagem e a realidade dos contos interpolados nessa ficção para ilustrar quanto são problemáticas as últimas questões que permeiam a filosofia e atingir o paradoxo essencial que o debate sobre elas retomaria, para deixá-las em suspenso e provocar a reflexão. "Se você pode me ouvir, se não percebe o discurso dos outros no meu discurso, as tra- 
mas dos outros em minhas incoerências, e não compreende nada da minha lógica que é toda a sociabilidade ao mesmo tempo que ontologia da matéria" (FONTENAY, 1981, p. 230, tradução nossa). ${ }^{2}$

Para Diderot, a lógica da narrativa e, portanto, as últimas questões da filosofia não podem ser desvinculadas da materialidade da vida, moléculas esparsas que se unem ao acaso, do mesmo modo que o encontro do autor com o leitor. As reflexões do leitor, respostas ao desafio do texto que produz um abalo nas formas habituais de pensamento, também provocam, consequentemente, uma retomada da própria experiência. Cito Diderot conversando com o leitor em Jacques: "[...] a natureza é tão variada, sobretudo quanto a instintos e caracteres, que não há nada de bizarro na imaginação de um poeta, de que a experiência e a observação não vos apresentem o modelo real" (DIDEROT, 1962, p. 79).

No momento em que a leitura provoca uma comoção, torna-se inevitável uma reflexão que dê sentido à vida e conduz a uma confusão, que, segundo Diderot, deve ser um dos primeiros efeitos da arte, efeito que o romance Jacques produz e propositadamente não resolve. A constatação da confusão que o texto provoca poderia propiciar a angústia do leitor, no entanto, a atitude que Diderot assume perante seus infindáveis paradoxos, neste e em outros romances, é uma postura que não tem a conotação de um desespero, pelo contrário, a colocação do paradoxo na sátira se dá sempre de uma maneira alegre, jovial, quase uma aceitação festiva.

Num diálogo entre amo e Jacques: "O Amo - Não há talvez sob o céu outra cabeça que contenha tantos paradoxos como a tua. Jacques - E que mal haveria nisso? Um paradoxo nem sempre é uma falsidade" (DIDEROT, 1962, p. 72).

Tentemos explicitar todas essas questões fazendo uma análise do próprio texto. Segundo Paul Vernière (1970), três temas se entrelaçam em Jacques, o fatalista, com o que ele denomina de "malícia estimulante": a viagem picaresca para lugar nenhum, o tema filosófico da fatalidade e a narração descontínua dos amores do herói e de Denise. Esse último tema poderia ser considerado o motivo de um suposto romance tradicional, mas, ele é colocado no início e retomado muitas vezes sem que, na verdade, ele apareça, já que antes de contar a história dos seus amores propriamente dita, Jacques insiste em narrar todas as circunstâncias que o levaram a conhecer sua amada e essas circunstâncias acabam monopolizando todo o tema, a tal ponto que a personagem surge tardiamente, sugerindo que esse tema seria um pretexto para tratar dos outros.

Os três temas se revezam incessantemente, dando a impressão de uma desordem e uma improvisação que seriam as características próprias dessa narrativa. A aparência caótica se

2 - "Si l'on n'entend que moi, si l'on ne perçoit pas le discours des outres dans mon discours, la trames des outres dans mon décousu, on ne comprend rien de ma logique que est toute socialité en même temps qu'ontologie de la matière". 
esvazia com a percepção de que o estilo narrativo é condizente com a discussão do tema da fatalidade e da liberdade. Há uma ambiguidade intrínseca, tanto na questão do tema do acaso ou necessidade e da liberdade quanto no romance que não o é, no sentido tradicional do termo. 0 próprio texto não pode ser lido como um romance tradicional; o que o autor nos propõe é muito mais um jogo do que uma leitura para passar o tempo. 0 começo já constitui um aviso de que este não é um romance comum. A história se inicia de uma maneira pouco convencional; o autor não nos situa nem no tempo, nem no espaço, as personagens irrompem sem nenhuma caracterização. 0 livro começa assim:

De que modo se encontraram? Por acaso, como todo mundo. Seus nomes? Que vos importa? Donde vinham? Do lugar mais próximo. Para onde iam? Sabemos lá para onde vamos? Que diziam? 0 amo, nada; Jacques dizia que seu capitão dizia que tudo o que nos acontece de bom e de mau cá embaixo estava escrito lá em cima (DIDEROT, 1962, p. 29).

As personagens não têm origem nem destinação. Essa forma de iniciar o romance produz um efeito desestabilizador que choca o leitor na medida em que ele não está preparado para esse começo. Muito mais desconcertante que essa falta de origem e destinação é a intervenção do narrador. Com efeito, à medida que adentramos na leitura, vemos surgir um narrador que constantemente se dirige ao leitor para provocá-lo com a sua insolência, afirmando ora que todo o poder está em suas mãos e que pode fazer de suas personagens aquilo que Ihe aprouver, ora exortando o leitor para que ele faça a continuação da história usando sua imaginação, ora incitando-o a refletir sobre qualquer narrativa interpolada, ora pedindo desculpas por todas as digressões, dispersões etc., ora reclamando da impaciência que o narrador pressupõe que o leitor habituado ao romance tradicional possa sentir, enfim, todas as incursões possíveis e imagináveis do narrador dentro da história. A realidade dessa conversa com o leitor contrasta frontalmente com a narração da viagem que nos parece inverossímil. A inverossimilhança da viagem entra em contradição também com outros contos que são interpolados e que têm sua verossimilhança não somente nos fatos, mas, concomitantemente, no estilo. Temos a impressão de que o autor intervém para que não esqueçamos sua presença e seu poder, para que recordemos aquelas narrativas que esquecemos na simultaneidade e também para demonstrar que seu estilo pode ser tão tradicional quanto o de outros romancistas.

Há vários contos inseridos na narração da viagem, alguns deles tão extensos que esquecemos a viagem e os amores de Jacques e que, ao contrário destes últimos, têm começo, meio e fim. A primeira e aparentemente mais importante história que surge é precisamente, a história dos amores de Jacques, no decorrer da viagem há outras histórias de outras personagens que os viajantes encontram no caminho ou que eles próprios conhecem e contam, comentando-as e refletindo a respeito delas. A história dos amores de Jacques somente se 
resolve, de maneira provisória, no final e ela se confunde com a narração da viagem. No entanto, no decorrer da viagem ela é interrompida tantas vezes (ou por peripécias e incidentes da viagem ou por outras histórias) que o leitor começa a duvidar que a história possa ter um fim. 0 próprio Jacques parece desejar que não acabe, e em repetidas ocasiões ele se nega a continuá-la alegando que o destino não quer que ele prossiga porque, cada vez que começa a contar, ocorre algum incidente que corta a sua fala. A expectativa criada no leitor de que essa história pode não acabar realmente se confirma, não somente porque o fim é deixado em aberto, mas também porque o narrador se nega a dar a última palavra, deixando notas ambíguas que o editor tenta interpretar.

No entanto, no início da leitura, o leitor não presta muita atenção à advertência de que esse não é um romance convencional e se sente frustrado nas primeiras interrupções da história desses amores. Quando avançamos na leitura depois de múltiplas interrupções, parece que vamos nos habituando a não ter o prosseguimento da história e começamos a nos envolver de tal forma com as outras e suas reflexões que acontece mesmo o imprevisivel, e, nós, leitores, a esquecemos, e esperar o seu fim já não parece ter tanto sentido.

Esse efeito do estilo torna-se tão sedutor que, ao contrário do que poderíamos esperar, já não possuímos a ansiedade do fim e permanecemos no divertido jogo a tal ponto que, quando alguma história se resolve, o efeito é o contrário do que é de hábito pensar, o fim nos surpreende e o que esperamos, na verdade, é que ela não se resolva para que o jogo não termine.

Quase todos os contos interpolados que outras personagens narram são interrompidos de alguma maneira, no entanto, para o leitor, que compreendeu as regras do jogo, esses cortes não irritam nem incomodam, produzem o estímulo da participação ativa. Essa participação torna-se efetiva quando esse leitor começa a tentar adivinhar até onde o narrador pretende chegar, onde e como ele vai encerrar essa história. Em muitas ocasiões, o autor se interrompe para perguntar ao leitor o que ele pensa a respeito do que está sendo contado. 0 narrador convida o leitor para participar, inclusive dando diversas soluções possíveis para um determinado caso, cutucando-o para que ele reflita a respeito do poder do narrador no que se refere à história.

Esse efeito da escrita de Diderot é interessante porque, quando se lê romances, não é habitual pensar: isto é uma fiç̧ão, permanece-se entretido com a história e não é comum uma reflexão a respeito das possibilidades ou nuanças que ela poderia ter. Ou seja, a reflexão que o romance tradicional possibilita não é a de questionar o próprio romance ou o sentido que podemos dar à escrita. A leitura de Jacques provoca a interrogação no sentido de pensar os limites da escrita e como é possivel que o autor denote o que ele pensa por meio das escolhas que faz. No limite, essa questão poderia ser radicalizada: Por que escolher? Por que não um jogo no qual todos os possíveis se misturem e por que não os deixar em aberto para que o leitor escolha? Nesse sentido, a leitura de Diderot subverte o hábito da leitura fácil, do pensamento mastigado e da solução evidente. Transforma a leitura de um simples romance 
no estímulo de um jogo de cruzamentos, simultaneidades, esporadismos, encruzilhadas, enfim, multiplicidade na unidade. Leitura que estimula a responder o apelo de participação que o autor constantemente abre tentando adivinhar o que se passará e, simultaneamente, a pergunta: É importante sabê-lo? Propicia o desejo de que não acabe nunca, de permanecer no jogo das questões. 0 fim da história é um grande exemplo desse efeito porque o autor o deixa em aberto para que a imaginação do leitor pense o que terá acontecido depois.

Cito: "Quanto a mim, paro por aqui, porque vos disse, dos dois personagens, tudo que sabia. [...] Observo, leitor, que isso vos aborrece; pois bem, retomai sua história onde ele a interrompeu, e dai-Ihe o fim que quiserdes" (DIDEROT, 1962, p. 257).

Tentemos ver alguns exemplos de como se abre esse diálogo com o leitor. Assim que Jacques principia a contar a história dos seus amores, o narrador o interrompe para afirmar:

\begin{abstract}
Como vedes, leitor, vou indo bem, é só de mim dependeria fazer-vos esperar um ano, dois anos, três anos pela narrativa dos amores de Jacques, separando-o do amo e submetendo cada um a todos os azares que entendesse. 0 que me impediria de casar o amo e torná-lo corno? De fazer com que Jacques embarcasse para as ilhas? De levar para lá o amo? De reconduzir os dois no mesmo navio? Como é fácil inventar histórias! Mas eles terão de suportar apenas uma noite má, e vós, esta dilação (DIDEROT, 1962, p. 30).
\end{abstract}

Podemos constatar que, logo após o primeiro diálogo entre as personagens, o narrador se dirige insolentemente ao leitor para preveni-lo de que seu domínio é total, com efeito, é muito fácil inventar histórias, ele poderia inventar o que quisesse para suas personagens e o leitor não teria possibilidade de intervir de forma alguma para evitá-lo. No entanto, é interessante perceber nesse primeiro corte narrativo o que aparentemente seria um pedido polido de desculpas por interrupções futuras, apelando para o testemunho do leitor no sentido de constatar sua boa intenção de seguir um caminho, mas haverá a necessidade de novos cortes que o acaso imporá.

Ambiguidade da insolência e da consideração para com o leitor, ambiguidade entre a liberdade de continuar como the agrade e a necessidade de prosseguir como "realmente ocorreu". Essa reflexão se cruza com a continuidade da viagem, em todos os momentos que ela surge, a escrita é como a viagem, pode-se escolher os caminhos onde sempre há encruzilhadas ou podemos andar ao acaso. Em um dos momentos em que retoma o prosseguimento da viagem:

Continuaram seu caminho, sempre sem saber para onde iam, apesar de saberem mais ou menos para onde queriam ir; enganando o tédio e a fadiga pelo silêncio e a tagarelice, como é de uso entre os que caminham, e algumas vezes entre os que estão sentados (DIDEROT, 1962, p. 79). 
E em outra passagem; "Mas, por Deus, leitor, direis, onde iam?... Mas, por Deus, leitor, responderei, quem sabe para onde vai? E vos, para onde ides?" (DIDEROT, 1962, p. 79). Quando estão hospedados num determinado ponto da viagem, a hospedeira pergunta-lhes para onde vão e Jacques responde que não sabem, o diálogo que se segue ilustra a ambiguidade de toda viagem: viajar por prazer ou por pena? 0 acaso decide. A pergunta ao leitor é um desafio para que ele pense nos próprios caminhos; o objetivo dessa reflexão seria o de provar que a pergunta não é tão simples de responder quanto parece. A narração da viagem possibilita a reflexão sobre a escrita e sobre o tema da fatalidade, os exemplos de cruzamento se tornariam infindáveis. Em uma passagem o autor nos diz:

Está bem claro que não faço um romance, pois que negligencio regras que um romancista não deixaria de empregar. Quem considerar o que escrevo como expressão da verdade terá menos probabilidade de errar do que quem supuser que se trata de uma fábula (DIDEROT, 1962, p. 79).

A cada continuação da viagem, sempre corresponde uma reflexão sobre a escrita e especulações a respeito do que um romancista faria nessa circunstância. Desta forma, há várias passagens em que as especulações acabam com a seguinte constatação: "Mas isto não é um romance" (DIDEROT, 1962, p. 39).

Nessas passagens ocorre a colocação do tema da necessidade. Haveria uma espécie de necessidade de verdade da narração. As especulações sobre as possiveis resoluções de impasses narrativos afirmando que se poderia optar por esta ou aquela maneira concluem com a afirmação da verdade dos acontecimentos: aconteceu como será contado. A necessidade de uma pretensa verdade estaria em contradição com a liberdade em diversas ocasiões aventada pelo narrador, para dispor de suas histórias. Após uma longa digressão, conversando com o leitor: "Compreendo leitor; quereis dizer-me: e os amores de Jacques? Supondes-me menos curioso que vos? Esquecestes que Jacques gostava de falar, sobretudo de si [...]" (DIDEROT, 1962, p. 170).

Em outra circunstância parecida, estabelece um diálogo do mesmo gênero e, se colocando na posição do leitor, reclama de uma nova digressão, afirma que o leitor não é muito polido porque não sabe bem o que quer, ora quer um conto, ora uma história, ora quer outra, é como se o autor adivinhasse aquele penetrar no jogo e o leitor pudesse, nesse momento, não somente aceitar com mais facilidade as regras já postas para brincar, mas também reclamar o seu uso quando o narrador as esquece. A necessidade pode, então, vir tanto da própria narrativa quanto do leitor que pode interferir nela. Nesse momento do texto, a questão da fantasia do autor e da fantasia do leitor é posta em discussão quando o narrador se insurge contra essa suposta falta de decisão do leitor dizendo que não é um autômato e que, se às vezes é necessário que ele siga a fantasia do leitor, também se faz necessário que ele avance na própria. 
Não deve haver monopólios da fala nem violências de imposição. 0 diálogo e as trocas são sempre necessários, as fantasias de todos devem se presentificar, devem circular no texto como numa conversa real e, se o leitor tem o direito de perseguir sua fantasia, direito que 0 autor Ihe outorga de bom grado, deve também ser respeitado o direito desse mesmo autor perseguir a sua. A partir do problema da fantasia podemos refletir em duas dimensões que, na verdade, são dimensões de uma mesma unidade. Em primeiro lugar, se é preciso seguir a fantasia é porque há um desejo que determina a vontade de concretizá-lo.

Em segundo lugar, o desejo que determina a vontade ocorre de ambas as partes, do narrador e do leitor. 0 primeiro poderia exercer a sua autoridade de autor e ser livre para escoIher sua fantasia, no entanto, o convite feito à participação determina uma parceria que é problemática na medida em que o diálogo democratiza e outorga direitos iguais ao leitor $\mathrm{e}_{\text {, }}$ apesar disso, a necessidade de seguir a própria fantasia permanece.

A ambiguidade entre necessidade e liberdade não é resolvida e, mais uma vez, a questão da verdade é colocada porque, se bem o autor é livre para escolher e mentir, ele deve dizer a verdade. "Vedes, leitor, como sou obsequioso: só de mim dependia [...] interromper a história do capitão de Jacques e impacientar-vos à vontade; mas, para isso seria preciso mentir, e não amo a mentira, a não ser que não seja útil e forçada" (DIDEROT, 1962, p. 77).

0 narrador tem conhecimento de que o leitor sabe que nada é verdade ou mentira nesse romance, que é simplesmente um romance, no entanto, ele joga com essa oposição entre as mentiras possiveis e as verdades que ele conta para demonstrar como esse tema da liberdade e da necessidade é complexo, como a fala pode estabelecer falsas verdades para sua utilidade ou para seguir seu desejo e como o diálogo democrático é problemático. Dialogando com o leitor, o narrador afirma:

\footnotetext{
A verdade, dir-me-eis, é muitas vezes fria, comum e sem graça; por exemplo, vossa última descrição do curativo de Jacques é verdadeira, mas que há nela de interessante? Nada. - De acordo - Se é preciso ser verdadeiro, há de ser como Molière, Regnard, Richardson, Sedaine; a verdade tem seus lados picantes que, quando se tem gênio, se apreendem. Mas quando não se tem? - Quando não se tem, que não se escreva (DIDEROT, 1962, p. 58).
}

Essa passagem prossegue em um diálogo suposto com o leitor, o que exige do narrador outra digressão. A partir desse diálogo, o autor se pergunta o que será dessa história, da história dos amores de Jacques, se ele se interrompe a toda hora e se o leitor insiste em interrompê-lo também. Apesar da necessidade de continuar a história, o autor cede a um suposto apelo do leitor. Tudo se inverte: o que era necessidade se transforma em liberdade, e o que era liberdade se transforma em necessidade. Inversão propiciada pelo diálogo aberto ao outro.

Nesse sentido, o autor adverte repetidas vezes para não se enganar com as aparências e tomar o verdadeiro pelo falso, e vice-versa. 0 leitor sempre pode objetar que há uma inveros- 
similhança nas histórias, mas o poeta sempre pode rebater que o modelo é a natureza que é também ele próprio e que: "Divirto-me em escrever sob nomes supostos as tolices que praticais; vossas tolices fazem-me rir; o que escrevo vos irrita" (DIDEROT, 1962, p. 206). A relação entre os dois se dá, pois, em vários níveis. Podemos estabelecer um paralelo entre essa reflexão que o autor desenvolve no diálogo com o leitor e a filosofia que Jacques defende ao longo do romance, em todos os momentos que ele pensa a respeito do que acontece, do que aconteceu e do que acontecerá, ou seja, com o fatalismo, Jacques repete constantemente:

Tudo que nos acontece de bom e de mau cá embaixo estava escrito lá em cima. Tem notícia, senhor, de algum meio com que anular esse decreto? Posso eu não ser eu? E desde que eu sou eu, posso agir de forma diferente da qual ajo? Posso eu ser eu num outro? [...] mas se estiver escrito lá em cima, [...] que pretende que eu faça?

0 amo - Estou pensando numa coisa: é se teu benfeitor teria ficado corno em virtude do escrito lá em cima, ou se assim fora escrito lá em cima porque irias cornear teu benfeitor. Jacques - Ambas as coisas, uma ao lado da outra, estavam escritas. Foi tudo escrito ao mesmo tempo. É como um grande rolo de papel que a gente desdobra aos poucos. Imaginais, leitor até onde poderia conduzir esta conversa sobre assunto de que tanto se tem falado e tanto se tem escrito há dois mil anos, sem avançar sequer um passo? (DIDEROT, 1962, p. 34).

Nessa perspectiva, a questão moral é problematizada, uma vez que as implicações da negação da liberdade, que se rende ao destino, fundariam uma moral condicionada ao que acontece, à materialidade da ação e, concomitantemente, colocaria em questão toda teologia ou metafísica. Diderot escreve nos pensamentos filosóficos que o homem é como Deus ou a natureza o fez, e Deus ou a natureza não faz nada de mal, portanto, a existência do vício e da virtude seriam naturais, próprios de uma vida que somente pode ser material. A natureza que a arte representaria é variada e heterogênea, ela produz diferentes seres indefinidamente e, portanto, a suposição de um ser que estivesse fora do universo, de suas matérias ou forças, parece impossivel. Assim como as personagens do nosso romance e os acontecimentos vividos por eles são produzidos pelo acaso, as moléculas materiais da natureza seriam passiveis de infinitas combinações formando organismos num fluxo perpétuo de metamorfoses arranjadas por acaso, sem projeto nem finalidade. Dessa maneira, pode-se concluir que tudo é natural.

Jacques não conhecia nem a palavra vício, nem a palavra virtude; a pessoa, para ele, nasce feliz ou infeliz. [...] 0 homem, segundo ele, se encaminhava tão necessariamente para a glória ou para a ignomínia. [...] Eu várias vezes o contradisse, mas sempre em pura perda. Com efeito, que replicar a quem vos diz: qualquer que seja a soma dos elementos que me 
compõem, eu sou um; ora, uma causa tem apenas um efeito a produzir; minha duração é apenas uma série de efeitos necessários. [...] A distinção entre um mundo físico e um mundo moral parecia-Ihe vazia de sentido. [...] Dessa maneira, poder-se-ia imaginar que Jacques não se rejubilava, nem se afligia por motivo algum; o que, todavia, não era verdade. Portava-se mais ou menos como vós e eu (DIDEROT, 1962, p. 172).

A descrição de Jacques elucida a unicidade de causa e efeito dentro da multiplicidade da natureza. 0 paradoxo entre uma natureza múltipla e a unidade do universo explicita-se no todo do universo no qual a matéria volta sempre no seu fluxo formando organismos diferentes, no entanto, produzidos pela mesma matéria e suas combinações que se dissolvem e misturam sob novas formas. Se as causas são aleatórias, os efeitos são necessários. 0 homem seria uma dessas combinações possiveis que nunca se repetem da mesma maneira, sua razão e sensibilidade são elementos múltiplos combinados em uma unidade que o transforma num ser original, mas não em um indivíduo como poderia ser entendido subjetivamente. Por esse motivo, ele se comporta, mais ou menos, como tudo mundo.

\begin{abstract}
Além do mais, bom homem, franco, honesto, bravo, dedicado, fiel, muito teimoso, mais ainda palrador, e aflito como vós e eu por haver começado a história dos seus amores sem quase nenhuma esperança de acabá-la. Aconselho-vos, assim, leitor, a esta resolução: à falta dos amores de Jacques, contentai-vos com as aventuras do secretário do Marquês de
\end{abstract} Arcis. (DIDEROT, 1962, p. 172).

A resignação do leitor tem sua correspondência na resignação do narrador, a necessidade de mais uma digressão combina com a fatalidade de Jacques. Apesar disso, da mesma maneira que a escrita, na qual a necessidade e liberdade se revezam paradoxalmente, o fatalismo de Jacques não é condizente com suas atitudes, há uma inconsequência entre sua filosofia e seu agir nas aventuras que eles vivem no decorrer do romance. A percepção dessa ambiguidade durante a leitura do romance nos coloca permanentemente em face da questão da liberdade e da necessidade: haveria uma suposta ambiguidade entre se acreditar na necessidade de tudo o que acontece e o agir virtuoso. Com efeito, o raciocínio deveria ser: se o comportamento humano não interfere no resultado e tudo vai ocorrer de acordo com a necessidade, logo, ninguém precisa agir bem ou mal, se não há liberdade, consequentemente, não haverá nem vício nem virtude. 0 agir virtuoso permaneceria vazio de sentido. As religiões resolvem essa questão prometendo recompensas ou castigos. Para Diderot, as religiões não se sustentam, cita o exemplo dos cristãos, se se tira deles a crença no inferno, a própria crença deixa de existir; eles precisam de castigo.

Diderot nos demonstra como essa questão do acaso e suas implicações éticas e práticas no agir não é tranquila na atitude de sua personagem Jacques quando se comporta de um 
modo que contradiz sua filosofia. Na verdade, ao longo de todas as peripécias do romance, Jacques não cessa de repetir que tudo o que acontece estava escrito lá em cima e, contrariando sua fala, sua conduta nunca é a de um mero espectador dos acontecimentos, ele age de acordo com o que no momento lhe parece o correto. Percebe-se na personagem um certo código de moral virtuosa que se revela no seu comportamento: ele intervém em muitas situações para modificar o curso dos acontecimentos.

As atitudes de Jacques poriam de manifesto que acreditar no destino não significa que deva se render a ele. Podemos ilustrar com vários exemplos: quando Jacques respeita sua amada ou quando se nega a fazer um arranjo com a mulher do cirurgião em troca de serviços prestados. "E porque seu marido me beneficiou, devo fazer mal a outro?" (DIDEROT, 1962, p. 106).

$\mathrm{Na}$ crítica das religiões e suas morais decorrentes está implícita essa recusa da troca mercantil, e significa que nós podemos ser ateus, acreditar na necessidade universal e, simultaneamente, agir de maneira virtuosa. Somente existiram as causas físicas, sendo o homem um átomo do todo, metamorfose que caminha com dois pés e que possui razão, Diderot reivindica para ele causas próprias, sem necessidade de apelar para causas que estariam fora da natureza. As causas próprias do homem o capacitariam para a virtude compreendida como natural. Apesar da necessidade, o homem deve possuir suas razões, deve-se tentar fazer o melhor, não o melhor hipócrita e sim o melhor dentro dos seus limites e circunstâncias. A aporia do fatalismo e da liberdade não se resolve, não obstante, pode-se formular uma moral prática que permitiria a convivência social, porque se bem é verdade que todo mundo quer ser feliz, também é preciso considerar que cada um deveria procurar sua felicidade sem prejuizo de que os outros a conquistem.

A complexidade do tema da fatalidade e suas implicações éticas podem ser pensadas também a partir do relacionamento entre as personagens. Os papéis de Jacques e seu amo são invertidos: o amo que deveria comandar a ação é descrito da seguinte maneira:

Tem poucas idéias na cabeça; se lhe acontece dizer algo sensato, é de maneira inconsciente e por inspiração. Como vós e como eu, ele tem olhos; mas a maior parte do tempo não se sabe se faz uso deles. Não dorme, nem vela; deixa-se existir: é a sua função habitual (DIDEROT, 1962, p. 48).

Logicamente, essa deveria ser a descrição de Jacques e não a de seu amo, seria a postura certa para alguém que acredita no destino.

Em várias passagens, o amo contesta a filosofia de Jacques, mas, concomitantemente, se deixa existir como se a compartilhasse. Jacques, inversamente, age mais como alguém que deseja intervir no destino: sai à procura de soluções que sempre terminam em confusões perigosas. 0 amo não compreende o motivo pelo qual ele enfrenta perigos que poderiam ser evitados. Podemos objetar que Jacques interfere porque, reconhecendo que não sabe o que 
está escrito lá em cima a respeito dessa situação ou de outra qualquer, nada pode ser previsto ou evitado. Nada pode garantir o que vai acontecer, mas o fato é que Jacques poderia se poupar da mesma forma que seu amo.

\begin{abstract}
0 Amo - E quem foi que escreveu lá em cima a felicidade e a infelicidade? Jacques - E quem foi que fez o grande rolo onde tudo vem escrito? Um capitão, amigo de meu capitão, teria dado com prazer um pequeno escudo para sabê-lo; quanto ao meu capitão, não teria dado um níquel, nem eu tampouco; de que me serviria? Evitaria, por isto, o buraco onde deverei sofrer queda fatal?

0 Amo - Creio que sim.

Jacques - Por mim, creio que não [...] (DIDEROT, 1962, p. 37).
\end{abstract}

Paradoxalmente, a servidão de Jacques em relação a seu amo se revela o contrário, pois, se há uma inconsequência entre seu agir e sua filosofia, também sua servidão não é assumida como tal. Sua obediência está condicionada à sua vontade e Jacques prova que é o amo que precisa dele e não o contrário. A demonstração de uma necessidade invertida torna-se ambígua em termos de narração: "[...] posto que Jacques e seu amo não são bons senão juntos e nada valem separados como Dom Quixote sem Sancho [...]" (DIDEROT, 1962, p. 78). Se aprofundarmos essa afirmação, podemos compreender que o próprio romance se tornaria impossivel sem duas personagens constantemente se debatendo, a questão da fatalidade não poderia ser apresentada e desenvolvida se Jacques não tivesse o contraponto de seu amo.

\footnotetext{
E ei-los metidos numa querela interminável a respeito de mulheres; um pretendendo que são boas, o outro, más: e ambos tinham razão; um, tolas, o outro, cheias de espirito: e ambos tinham razão; um, falsas; o outro, verdadeiras: e ambos tinham razão; um, avaras; o outro, liberais: e ambos tinham razão; um, belas; o outro, feias: e ambos tinham razão [...] (DIDEROT, 1962, p. 46).
}

Da mesma maneira que esse contraponto é necessário, no segundo plano do diálogo, o do narrador com o leitor, a conversa com o leitor e sua interferência nem sempre tranquila é ambígua, no entanto, necessária para comover o leitor. A ambiguidade está na narrativa de um romance que não o é, abrindo sempre espaço para que o leitor intervenha e participe, incitando sua reflexão a respeito da necessidade e de seu poder tanto na linguagem quanto na vida.

Quando Diderot interpola, na sequência narrativa, especulações sobre o que poderia ser feito com a história, parece-me que o autor deseja que nós leitores percebamos seu poder como narrador e também o nosso. 0 paradoxo colocado em vários níveis permite uma reflexão em vários níveis. No momento em que o autor afirma que Jacques não é diferente de 
nós, ele age mais ou menos como todo mundo, o paradoxo da personagem seria, concomitantemente, o de nossa vida; brincando com a vida de suas personagens, convidando-nos a brincar com ele, na mesma medida em que Jacques não é diferente de nós, estabelece um jogo no qual todos estamos implicados e do qual não podemos escapar. Impossível dividir, separar. A natureza é uma, a física e a moral não se distinguem, como Jacques e seu amo, como a liberdade e a necessidade, como o narrador e o leitor. A narrativa expressa essa unidade na multiplicidade engendrando novas relações. Diderot impede as divisões tranquilizadoras, o acaso e a liberdade se mesclam numa provocação à reflexão para nos darmos conta de que essas questões não podem ter respostas absolutas e definitivas, não é possível resolvê-las de maneira clássica. 0 estilo ambíguo de Diderot retrata o paradoxo e a complexidade. Segundo Fontenay, o estilo de Diderot é como sua concepção de natureza, unidade que, paradoxalmente, se dá no esporádico e na explosão e que nunca deixa de ensaiar novas formas sem jamais submeter-se a um fim:

Possibilidade, necessidade, toda fecundidade lucrativa das cascatas de declinações, a escrita de Diderot, jogo final da questão que se revira e se aventura por si mesma, cai de maneira aleatória. As seqüencias são quase reversiveis e não há curvas finais. (FONTENAY, 1981, p. 17, tradução nossa). ${ }^{3}$

0 estilo de Diderot exprime o desejo de deixar todas as questões em suspenso, constituindo-se num perigo que abala qualquer sistema e qualquer fixidez. Em consequência, o romance rompe com o próprio gênero, e, tal como a matéria, a escrita se aventura num jogo que inquieta e dissolve toda certeza, pulveriza todas as tentativas de ordem. 0 diálogo aberto ao outro é um caminho permeado de encruzilhadas que incessantemente desmistificam o papel autoritário do autor, considerando a palavra do outro, transforma o leitor em copartícipe da aventura de escrever. 0 leitor pode reclamar da qualidade do texto ou das consequências amorais que sua obra poderia suscitar. Se a obra é boa, ela proporcionará prazer, se é má, não interferirá, o leitor continuará sendo o que é. No entanto, se o leitor se outorga o direito de criticá-la, ele estará sendo hipócrita, já que o autor somente transfere para sua obra o que é natural, e a natureza não faz nada de mal.

Conversando com o leitor, o autor afirma: "E que mal vos teria feito a ação genital, tão natural, tão necessária e justa, para excluir de vossas conversas seu sinal representativo, e imaginar que vossa boca, vossos olhos e ouvidos seriam por ela maculados?" (DIDEROT, 1962, p. 206). A hipocrisia moral é ironizada nesse mesmo diálogo com o leitor:

3 - "Hasard, nécessité, fécondité toute lucrécienne des cascades de déclinaisons, l'écriture de Diderot, ultime jeu de la matière qui se retourne sur elle-même et s'aventure en elle-même, relève en quelque sorte de l'aléatoire. Les séquences sont quasi réversibles et il n'y a pas de tournants définitifs". 
Leitor, falando-vos francamente, considero que o pior, de nós dois, não sou eu. Como ficaria satisfeito se me fosse tão fácil precaver-me contra vossas torpezas, como o é para vós precaver-vos contra o tédio ou o perigo de minha obra! Vis hipócritas, deixai-me em paz [...] desculpo-vos os atos, desculpai-me a palavra (DIDEROT, 1962, p. 206).

A desordem, a simultaneidade e a sucessão de narrativas entrecruzadas, a indivisibilidade, o paradoxo da unidade e da multiplicidade, o diálogo e a ironia, corroem o hábito da leitura e do pensamento tradicional, todos nos tornamos autores e leitores, autor e leitor se relacionam na necessidade e liberdade mútua produzindo uma escrita que somente o diálogo poderia suscitar. "Disponha de meu trabalho como lhe agrade. Você é o mestre de aprovar e contradizem, somar, subtrair" (FONTENAY, 1991, p. 231, tradução nossa). ${ }^{4}$

0 final do romance que não termina retrata a abertura para o outro. A narrativa poderia impor de forma veladamente violenta um domínio do autor sobre seus leitores, no entanto, o estilo subversivo de Diderot tem a eficácia de demonstrar o quanto as falas podem ser dominadoras, desafia o leitor a se insurgir contra verdades estabelecidas, comovendo sua visão de mundo e os dogmatismos filosóficos, negando origem e finalidade, ou seja, respostas últimas, instaura o paradoxo: procura de uma verdade que consiste na própria procura e não na descoberta.

\section{Need or freedom: a discussion from Diderot's novel, Jacques, the fatalist}

Abstract: The purpose of this article is to think about Denis Diderot's reflection in relation to his philosophy, based on the novel Jacques, the fatalist. Considering the extent of Diderot's work; that he is not a systematic philosopher but an author who points in different directions, therefore interdisciplinary, and because what is usually called the Jacques novel, the fatalist is, in fact, the anti-romance. Diderot must be situated in the historical context of the 18th century, in which the thinkers we used to call Enlightenment inaugurate new ways of thinking, a new rationality that goes beyond clear and distinct ideas, which rises up against closed systems and which opens up to criticality, for passionate controversy, in short, everything that announces the French Revolution.

Keywords: Freedom. Enlightenment. Romance. French Revolution. Rationality.

4 - "Disposez de mon travail comme Il vous plaira. Vous êtes le maitre d'approuver e de contredire, d'ajouter, de retrancher". 


\section{REFERÊNCIAS}

DIDEROT, D. Diderot. Obras IV. Jacques, o fatalista e seu amo. São Paulo: Perspectiva, 2006.

DIDEROT, D. Jacques, le fataliste. Chronologie et préface par Paul Vernière. Paris: Flammarion, 1970.

DIDEROT, D. Le neveu de Rameau. Paris: Flammarion, 1983.

DIDEROT, D. O sobrinho de Rameau. São Paulo: Hedra, 2007.

DIDEROT, D. Obras romanescas: Jacques, o fatalista. São Paulo: Difusão Europeia do Livro, 1962.

DIDEROT, D. OEuvres choisies. Paris: C. Reinvald, Libraire-Editeur, 1884.

FONTENAY, E. de. Diderot ou le matérialisme enchanté. Paris: Grasset, 1981.

GRIMALDI, N. Quelques paradoxes de l'esthétique de Diderot. Revue Philosophique de la France et de l'Étranger, n. 3, 1984.

JAUSS, H. R. Le Neveu de Rameau. Dialogique et dialectique (Ou: Diderot lecteur de Socrat et Hegel lecteur de Diderot). Revue de Métaphysique et de Morale, n. 2, 1984.

LEDUC-FAYETTE, D. Diderot, le desordre, le mal. Revue Philosophique de la France et de l'Étranger, n. 3, 1984.

MARQUET, J. F. La monadologie de Diderot. Revue Philosophique de la France et de l'Étranger, n. 3, 1984.

ROMANO, R. Diderot, Penélope da Revolução. Revista USP, n. 1, São Paulo, mar./abr./maio, 1989.

ROMANO, R. Silêncio e ruido. A sátira em Denis Diderot. Campinas: Editora da Unicamp, 1996.

VERNIĖRE, P. Préface. In: DIDEROT, D. Jacques, le fataliste. Paris: Flammarion, 1970. 